\title{
Additive manufacturing of TiAl-based alloys
}

\author{
Thywill Cephas Dzogbewu* \\ Department of Mechanical and Mechatronics Engineering Central University of Technology, Free State, Bloemfontein, \\ South Africa
}

Received: 25 July 2020 / Accepted: 9 September 2020

\begin{abstract}
The ever-increasing demand for developing lightweight, high-temperature materials that can operate at elevated temperatures is still a subject of worldwide research and TiAl-based alloys have come to the fore. The conventional methods of manufacturing have been used successfully to manufacture the TiAl-based alloy. However, due to the inherent limitations of the conventional methods to produce large TiAl components with intricate near-net shapes has limit the widespread application and efficiency of the $\mathrm{TiAl}$ components produced using conventional methods. Metal additive manufacturing such as Electron Beam Melting technology could manufacture the TiAl alloys with intricate shapes but lack geometrical accuracy. Laser powder bed fusion (LPBF) technology could manufacture the TiAl-based alloys with intricate shapes with geometrical accuracy. However, the inherent high rate of heating and cooling mechanisms of the LPBF process failed to produce crack-free TiAl components. Various preheating techniques have been experimented, to reduce the high thermal gradient and residual stress during the LPBF process that causes the cracking of the TiAl components. Although these techniques have not reached industrial readiness up to now, encouraging results have been achieved.
\end{abstract}

Keywords: TiAl / conventional methods / additive manufacturing / electron beam melting / laser powder bed fusion

\section{Introduction}

Titanium aluminides (TiAl) based alloys represent an important class of high-temperature structural materials providing a unique set of physical and mechanical properties that can lead to substantial payoffs in aircraft engines, industrial gas turbines, and automotive parts [1]. Their technological maturity has been proven by recent applications, of the alloy in the low-pressure turbine of the (General Electrical) GEnX jet engine [2]. The significant advancements in the understanding of the relationships among composition, processing, microstructural characteristics, and properties have made the infrastructure and knowledge base of TiAl alloy production by the conventional methods (extrusion, forging, casting) very mature. As a result, the continued confidence in TiAl-based alloys for high-temperature engineering applications would continue to increase. As noted by Bewlay et al. [3], the extensive investigations of TiAl alloys have enabled their commercial implementation in the aerospace and automotive industries. The GEnx ${ }^{\text {TM }}$ engine is the first commercial

\footnotetext{
* e-mail: thydzo@yahoo.fr
}

aircraft engine that used Ti-48Al-2Cr-2Nb (TiAl 48-2-2) for their low-pressure turbine blades. GE recently used new $\beta$-stabilized TiAl alloy Ti-43.5Al-4Nb-1Mo-0.1B (at.\%) known as $\mathrm{TNM}^{\mathrm{TM}}$ to manufacture low-pressure turbine (LPT) blades for PW1100G ${ }^{\mathrm{TM}}$ engines.

The outstanding thermo-physical properties of $\mathrm{TiAl}$ alloys is due to their ordered structure, lightweight, high melting point, low density (only half as the one of Nickel), high elastic modulus, low diffusion coefficient, good structural stability, resistance against "titanium fire", good creep properties, good oxidation, and corrosion resistance, and high ignition temperature when compared to classical titanium alloys, steels and nickel-based superalloys in the temperature range of $500{ }^{\circ} \mathrm{C}$ to $900{ }^{\circ} \mathrm{C}[4-6]$. The fore mention attributes of $\mathrm{TiAl}$ alloys make them considered as a potential replacement for the heavyweight Ni-based superalloys for use in turbine blades and divergent flaps in nozzles of high-speed gas turbine engines [7,8]. The replacement of Ni-based superalloy parts with TiAl-based alloys could reduce the structural weight of high-performance gas turbine engines by $20-30 \%$, which would enhance engine performance and fuel efficiency [9].

Rolls-Royce has used Ti-45Al-8Nb to produce compressor blades for automobile application by extrusion and 
forging. The parts demonstrated that the alloy offers excellent high-temperature strength [10]. However, they reported that the processing costs are very high and though the blades are of few centimeters the microstructure is inhomogeneous. The blades are porous with $80 \%$ rejectrate. Manufacturing of larger components using the conventional methods would result in a higher level of the inhomogeneous microstructure and higher rate of part rejection. As the current interest of TiAl alloy tends to be in the aerospace and automotive industries [11], the components of interest would definitely tend to be large parts, which implies the production of more inhomogeneous parts, if no suitable alternative method(s) of production is not identified.

The TiAl alloy parts that are produced by casting are cost-effective but failed to meet aerospace requirements of reliability due to the reactivity of molten TiAl alloys. Producing TiAl alloy by casting lead to relatively coarse microstructure with metallurgical defects such as porosity shrinkage, poor room-temperature mechanical properties, and inhomogeneous microstructure. An attempt to rectify the problem by using cold wall crucibles and preheated molds has led to the production of parts with large alpha grain sizes and long (coarse grain) lamellae. This type of microstructure leads to an increased tendency to pre-yield cracking, low fatigue life, and low ductility [1]. To avoid the fore mention drawbacks simple shape and moderate dimension of $\boldsymbol{\gamma}$-TiAl alloys were produced. To satisfy the industrial requirements of producing geometrical, technical, and functional TiAl components of complex shapes and homogenous microstructure, an alternative processing route(s) need to be exploited [12].

The mechanical properties of a material are the main determining factors for qualifying it for a specific application [13], however, for improved energy efficiency and power for highly engineered products; such as the aircraft engines, industrial gas turbines and automotive parts, near-net shapes that would enhance the geometrical, technical and functional properties of the components has become very paramount. These functional requirements of near-net shapes of complex geometries (e.g. back tapers, intricate cooling channels, customized porous structures, and special lattices or hollow structures) make additive manufacturing (AM) an attractive manufacturing technology to be exploited for manufacturing TiAlbased alloys with specific geometrical characteristics for the high-temperature operations. Besides, the AM processing routes are more promising to produce more isotropic microstructures [14]. The TiAl alloys have high mechanical strength both at room temperature and high temperature due to its intermetallic nature $[1,2,7]$. These high thermal properties give it unique characteristics for high-temperature applications. Unfortunately, the very properties that make the material attractive for hightemperature operations also make it difficult to process via conventional methods [15]. The limitations of using the classical methods of producing bulk TiAl-based alloys have put materials science researchers on the urge of experimenting with metal additive manufacturing (MAM) technologies such as powder bed fusion for possible solutions.

\section{Metal additive manufacturing of TiAl-based alloys}

Additive manufacturing (AM) is the process by which parts are joined or solidified from a powder feedstock. It is a manufacturing technique capable of producing complex geometry components layer-by-layer. AM machines are grouped and categorized according to the type of feedstock material and energy source used for the production process. Powder bed fusion (PBF) is one of these categories and comprised of electron beam melting (EBM) and laser powder bed fusion (LPBF) machines. The PBF machines build three-dimensional (3D) components in a layer-wise manner using metallic powder feedstock. Electron beam or laser power melt and solidified the metallic powder in a layer-wise fashion based on a 3D CAD model instead of removing waste material in different steps as used by the conventional methods. PBF manufacturing technology is eco-design topology optimization technology that allows very complex parts to be created monolithically which provide almost unchallenged freedom of design $[16,17]$. Using the PBF technology to manufacture the TiAl-based components with specific geometrical and functional nearnet-shape characteristics for high-temperature operations would greatly reduce the time spent on manufacturing, reduce assembly and maintenance costs, avoid waste of manufacturing materials, improve performance reliability and weight reduction. The use of such intricate geometries would lead to fuel consumption and emission reduction and sustainable development at a lower cost $[2,3,18]$.

Bewlay et al. [3] reported that GE began to explore near-net-shape manufacturing as an alternative to the initial conventional gravity casting plus machining approach of producing TiAl-based alloy low-pressure turbine blade which powers Boeing 787 and 747-8 aircraft. Their effort led to the production of GEnx engine with great propulsion efficiency of a $20 \%$ reduction in fuel consumption, a $50 \%$ reduction in noise, and $80 \%$ reduction in $\mathrm{NO} x$ emissions compared with prior engines in its class. More than 40,000 TiAl low-pressure turbine blades have been manufactured using AM for the GEnxTM 1B (Boeing 787) and the GEnxTM 2B (Boeing 747-8) applications. GE Aviation used $\gamma$-TiAl-based alloys for the manufacturing of the low-pressure turbine blades $[2,3]$. The literature reveals that the $\gamma$-TiAl phase is considered as the most suitable candidate for the replacement of Ni-based superalloys at

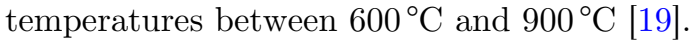

The TiAl phase diagram (Fig. 1) reveals that the TiAl based alloy can solidify in a single-phase y (TiAl) state when the Al content exceeds almost 50-56 at.\% [ $\mathrm{Ti}(50-56) \mathrm{Al}]$ and in two phases $\gamma(\mathrm{TiAl})+\alpha_{2}\left(\mathrm{Ti}_{3} \mathrm{Al}\right)$ when the $\mathrm{Al}$ composition is between 44 and 49 at.\% [ $\operatorname{Ti}(44-49) \mathrm{Al}$. Single-phase alloys attracted attention initially because of their excellent resistance to environmental attack (oxidation and hydrogen absorption). However, the single-phase y (TiAl) alloys suffer from poor ductility and fracture toughness at room temperature. Much effort has not been made to overcome the limitations of the single-phase $\mathrm{y}$ (TiAl) alloys, as a result, interest in these engineering alloys has diminished. However, extensive industrial and academic based research had been going on to improve the structural 


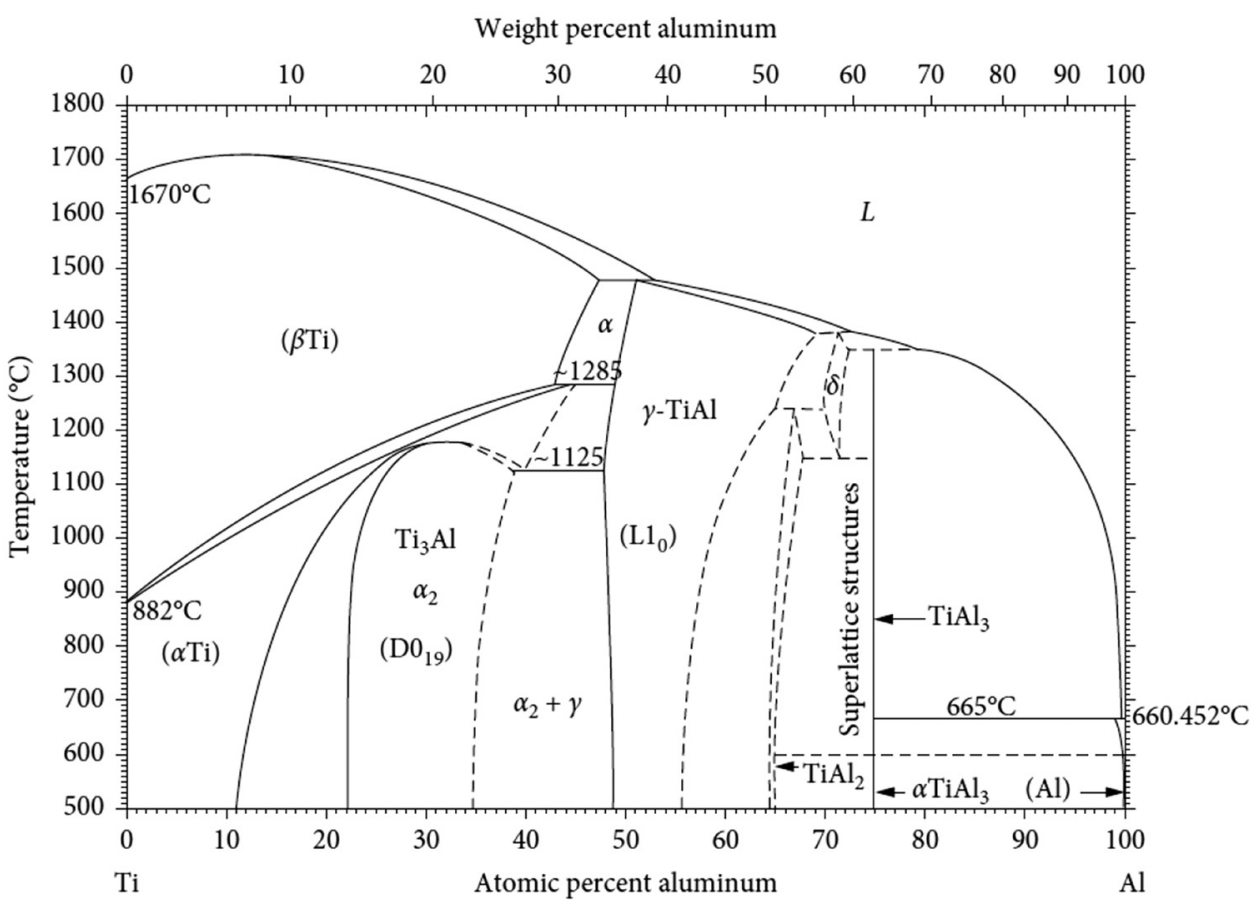

Fig. 1. TiAl phase diagram [50].

applications of the two-phase $\gamma(\mathrm{TiAl})+\alpha_{2}\left(\mathrm{Ti}_{3} \mathrm{Al}\right)$ alloys [8-11]. The objective has essentially been to achieve balanced mechanical properties such as ductility, tensile strength, toughness, and creep strength via improved alloy chemistry, microstructural control, and process route (manufacturing technology) [10,11]. The two-phase $\gamma(\mathrm{TiAl})+\alpha_{2}\left(\mathrm{Ti}_{3} \mathrm{Al}\right)$ $\mathrm{Ti}-(44-49) \mathrm{Al}$ alloys with various elemental compositions have been vigorously investigated from three designated groups: Ti-(44-49) $\mathrm{Al}-(1-3) \mathrm{X}_{1}-(1-4) \mathrm{X}_{2}-(0.1-1) \mathrm{X}_{3}\left(\mathrm{X}_{1}=\mathrm{V}\right.$, Cr, Mn; $\mathrm{X}_{2}=\mathrm{Nb}$, Ta, W, Mo; $\mathrm{X}_{3}=\mathrm{Si}, \mathrm{C}, \mathrm{B}, \mathrm{N}, \mathrm{P}, \mathrm{Se}, \mathrm{Te}, \mathrm{Ni}$, $\mathrm{Mo}, \mathrm{Fe}$ ) [8]. The $\mathrm{X}_{1}$ alloying elements nearly double the twophase TiAl alloy room temperature ductility. The $\mathrm{X}_{2}$ elements are very effective in improving the oxidation resistance and solid-solution strengthening of the two-phase TiAl alloys and the $\mathrm{X}_{3}$ elements improve creep resistance, oxidation resistance, and ductility of the alloy [8-11]. Depending on the process route, thermal treatment, and composition the TiAl-based alloys can exhibit three different microstructures: gamma, duplex, fully lamellar microstructures [20,21]. Gamma and duplex microstructures give rise to high strength and some ductility but poor creep resistance, low fatigue strength, and low fracture toughness. The fully lamellar microstructure, consisting of the TiAl ( $\gamma$-phase) and a small volume fraction of $\mathrm{Ti}_{3} \mathrm{Al}\left(\alpha_{2}\right.$-phase $)$ microstructures demonstrates high creep resistance, higher fracture toughness and crack propagation resistance which makes such phases suitable for high-temperature applications [20]. Besides the good mechanical properties offered by TiAl ( $\gamma$-phase) and $\mathrm{Ti}_{3} \mathrm{Al}$ $\left(\alpha_{2}\right.$-phase), they also offered superior oxidation resistance compared to the other phases for high-temperature applications [21].

In the view of Thomas et al. [12], AM could contribute significantly to the manufacturing of the TiAl alloys parts for the high-temperature applications. Because it reduces the time to market production; lead time by reducing machining and joining steps and by avoiding timeconsuming tooling reworking, buy-to-fly ratio owing to a low material waste factor, weight saving, and adding supplementary functions such as cooling channels. These characteristics make the AM technology a cost-effective method for producing aerospace engines as compared to the classical methods of manufacturing.

\subsection{Electron beam melting of TiAl-based alloys}

Cormier et al. [15] use the EBM method to investigate the possibility of manufacture bulk intermetallic Ti-47Al$2 \mathrm{Cr}-2 \mathrm{Nb}$ alloy. One set of the samples were produced using pre-alloyed powder and the other with elemental blended powders mixed in appropriate ratios. The optical and electron microstructure observation of the samples manufactured with the pre-alloyed TiAl powder reveals lamellar $\alpha_{2}+\gamma \mathrm{TiAl}$ microstructure as in the conventional method. Murr et al. [22] experiment with $\gamma \mathrm{TiAl}$ powder with nominal composition $\mathrm{Ti}-47 \mathrm{Al}-2 \mathrm{Nb}-2 \mathrm{Cr}$ (at.\%) and precursor powder with appropriate ratios. For the precursor powder, it was observed that some of the aluminum and titanium powder remain un-melted. The microstructure of the samples manufactured with the precursor powder was largely $\alpha_{2}$-phase rich $\left(\mathrm{Ti}_{3} \mathrm{Al}\right)$ while the samples manufactured with the pre-alloyed powder exhibit $\gamma \mathrm{TiAl}$ grain structure with lamellar $\gamma / \alpha_{2}$ colony structure. Rastkar and Shokri [23] investigate the possibility of producing $\mathrm{Ti}-45 \mathrm{Al}-2 \mathrm{Nb}-2 \mathrm{Mn}-1 \mathrm{~B}$ (at.\%) with a harder surface layer at a high beam energy $(350 \mathrm{~W})$ with varying scanning speed using EBM technology. It was explained that at high beam energy and scanning speed cooling rate is fast enough to largely suppress $\alpha$ to $\alpha_{2}$ 

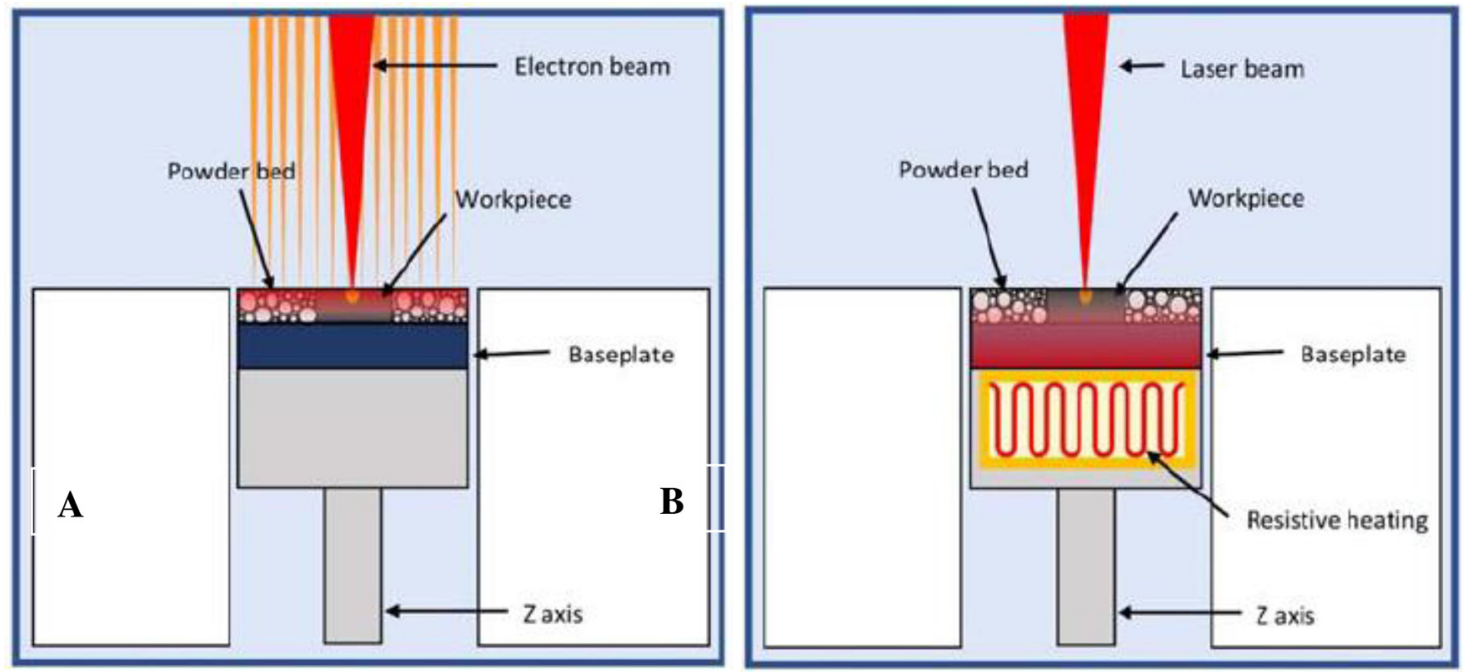

Fig. 2. The layout design of AM machines; (A) EBM with a pre-scanning heating system (B) LPBF with a pre-heating system at the based plate [27].

phase transformation and promote a microstructure with the hard ordered B2 phase on the surface of the bulk material.

EBM was the main AM method that scholars have experimented with in producing the $\mathrm{TiAl}$ alloys near-netshape, probability due to the EBM high preheating temperatures [24] which lowers the stress buildup leading to the successful production of crack-free TiAl 3D structures. Though there are issues of Al lost during the EBM process, the current literature has pointed out that optimized processing conditions have already been achieved for producing sound and crack-free TiAl materials by EBM processes $[12,22,25,26]$. The successfully using of the EBM technology to manufacture the TiAl-based alloys is due to the preheating system (Fig. 2A) employed during the EBM manufacturing process [27]. Due to the preheating system, the powder bed remains at high temperature in the order of $1000^{\circ} \mathrm{C}$ [22] causing the thermal gradient and residual stress to be lowered resulting in the manufacturing of crack-free TiAlbased alloys. However, EBM manufacturing technology lacks geometrical precision due to the melt pool dimension $[22,26,28]$. The lack of geometrical precision requires larger machining allowances and the post-processing stage becomes very complicated due to the complex geometry of the product [27]. Machining the products to the final precise dimensions would result in wasting the material. As a result of the inherent limitations posed by the EBM, researchers begin to experiment with other PBF technologies such as LPBF manufacturing process which have demonstrated a great geometrical accuracy when used for other metal alloys such as titanium and steel based alloys $[17,29,30]$.

\subsection{Laser powder bed fusion of TiAl-based alloys}

The literature reveals that LPBF has been used extensively for several metallic materials such as titanium and steel based alloys $[17,29,30]$ but not much for TiAl alloys. It was only about a decade ago that researchers attempt to produce TiAl-based alloys using the LPBF process due to its promising attraction for dynamic applications at high temperatures. Unfortunately, the record shows that the pioneers faced a challenge of manufacturing crack-free TiAl samples [14,26,31]. Several attempts were made to determine the optimum process parameters that could yield crack-free TiAl samples but to no avail. It was explained that the high rate of heating and cooling $\left(10^{4}-10^{6} \mathrm{~K} / \mathrm{s}\right)[32,33]$ of the LPBF process which favours the build-up of residual stress was the reason for not being able to suppress the cracking effect.

The studies of Vilaro et al. [14] focus on the influence of the process parameters on the rate of cracking of Ti-47Al$2 \mathrm{Cr}-2 \mathrm{Nb}$ (at.\%) samples produced by LPBF process. The thermal conditions during solidification (Temperature gradient $-G$, solidification rate $-Z$, cooling rate $-T$ ) were optimized. An increase of the $\mathrm{G} / \mathrm{Z}$ ratio progressively changes the solidification behaviour from dendritic to cellular up to planar front growth whereas the G.Z determines the microstructure characteristics. Thus, a careful combination of the process parameters could slow down the cooling rate which would enable the manufacturing of crack-free TiAl alloys. It was reported that at a slower scanning speed and wider beam diameter the molten liquid takes a longer time to solidify and induces a lower temperature gradient of the solidification front as well as a lower cooling rate. The optimum process parameters (scanning speed $0.02 \mathrm{~m} / \mathrm{s}$, laser beam diameter $380 \mu \mathrm{m}$, laser power $60-250 \mathrm{~W}$ ) were only able to reduce the cracking effect but could not suppress it completely. It was observed that the cracks start from the interface and propagate along the building direction $\mathrm{Z}$, hence the substrate was maintained at $500^{\circ} \mathrm{C}$ trough out the experiments to relive the material of residual stress while the building process continuous.

Loeber et al. [26] produce Ti-48Al-2Cr-2Nb by LPBF in comparison to EBM samples. It was reported the LPBF samples show no clear microstructure under the SEM-SE 
(secondary electron) contrast, thus no clear statement of the as-built LPBF samples microstructure can be made. The samples were heat-treated at $1400^{\circ} \mathrm{C}$ for $2 \mathrm{~h}$ after which a fine lamellar microstructure was observed. The elastic modulus value obtained for the samples $(50 \pm 13 \mathrm{GPa})$ was about one third lower than what is normally reported for TiAl alloys using the conventional methods of manufacturing [25], which is due to the presence of pores (cracks) in the samples. The amount of aluminum lost is lower for the LPBF samples $(0.2 \mathrm{wt} . \%)$ than that of EBM (0.3 wt.\%). To overcome the cracking of the LPBF samples due to the high-temperature gradient and residual stress which is inherent in the manufacturing process of the LPBF process, researchers begin to adopt a preheating strategy in an attempt to produce crack-free LPBF samples. Thomas et al. [12] suggested that preheating and conventional post-heat treatment are a possible means of producing crack-free TiAl samples with uniform microstructure.

Gussone et al. [31,34] demonstrate the possibility of producing crack-free Ti-44.8Al-6Nb-1.0Mo-0.1B (at.\%) alloy using LPBF by intrinsic heat-treatment (preheating temperature).

During the manufacturing process, a heat cycle is placed between the new layer and the previous layers. The successive heating of the solidified layers as new powder layers were deposited and melted is termed intrinsic heat treatment. The heating cycling process leads to the production of graded microstructure in the building direction. To suppressed crack formation the baseplate was held at $800^{\circ} \mathrm{C}$ during the manufacturing process. The selected LPBF process parameters were laser power $80 \mathrm{~W}$, scanning speed $0.45 \mathrm{~m} / \mathrm{s}$, and powder layer thickness $30 \mu \mathrm{m}$. Holding the baseplate at $800{ }^{\circ} \mathrm{C}$ the intrinsic heat treatment enables the production of very fine-near lamellar $\left(\alpha_{2} / \gamma\right)$ microstructure. A further improvement in the microstructure was obtained by hot isostatic pressing (HIP). The HIP process leads to a globular microstructure with a few regions appearing to have originated from the former $\left(\alpha_{2} / \gamma\right)$ lamellar structure. The authors concluded that despite achieving almost full density a tension crack evolves from the side of the specimen towards the middle indicating an increased thermal gradient between the outer perimeter and the middle section of the samples as a result of the rapid heating and cooling of the LPBF manufacturing process.

As explained by Thomas et al. [12] generally the LPBF process induces higher cooling rates that make it difficult to alleviate the cracking effect, however, manufacturing of industrial components is highly possible if a preheating source could be employed and post-heat treatment to homogenized the microstructure are conducted. However, as depicted in Figure 2, the EBM pre-heating system (Fig. 2A) is designed to keep the temperature of the powder bed at a high-temperature (about $1000{ }^{\circ} \mathrm{C}$ ) thorough out the manufacturing process prior to the melting of the powder while the LPBF pre-heating system is focused on preheating of the based plate (Fig. 2B). This is because the based plate normally acts as a heat sink which would trigger higher thermal gradients and cooling rates resulting in a very high thermal stress at the bottom of the samples

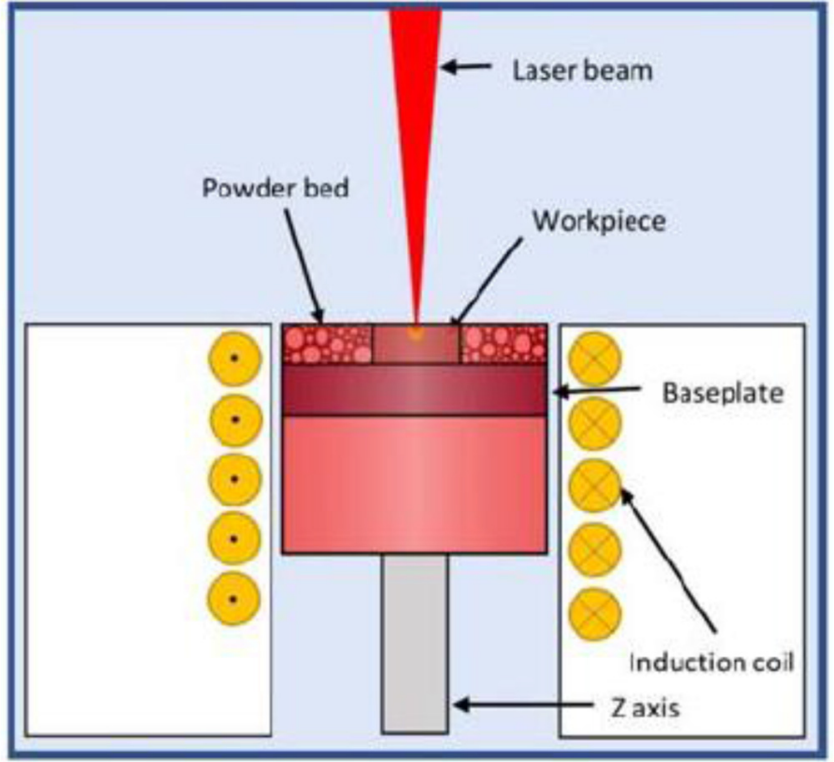

Fig. 3. The conceptualized designed of the LPBF machine with pre-heating system [27].

which would serve as a crack initiation point [14]. The literature reveals that different based plate preheating techniques (IR heaters [35-37], fast scanning laser beam [38-40], second defocused laser beam [41], substrate resistive heating $[42,43]$ and baseplate induction circuit $[31,34,44])$ have been applied in the LPBF manufacturing process to prevent the crack formation. These approaches of based plate preheating were able to lower local stresses near the base plate and allowed the manufacturing of crack-free samples only at the base plate level but lost their effectiveness when a full-scale component must be manufactured. The LPBF process works by lowering the base plate each time a new layer is built, hence for a large component, the effect of the preheating of the base plate becomes inefficient to keep the powder bed at high temperature to prevent crack formation. Since the industrial panorama reveals a high demanded for TiAlbased alloy components of larger size, intricate shapes with great geometrical accuracy [1-3], there is a need for further research into the possibility of producing crack-free TiAlbased alloy of large size, intricate shapes with geometrical accuracy.

\section{Encouraging results}

To overcome the inherent limitations of the high rate of heating and cooling (high thermal gradient and residual stress) mechanism of the LPBF process to produce crackfree TiAl intricates (near-net-shapes) components of precise geometrical configurations; a new preheating of the powder bed is required. A conceptual design of a new pre-heating system (Fig. 3) for the LPBF technology was recently experimented with by Caprio et al [27]. With the novel design, the authors were able to maintain the preheating temperature of the base plate and the previously 
solidified layers at $800{ }^{\circ} \mathrm{C}$ throughout the LPBF process. A 50-layer component was produced without crack formation, however, there were pores (wholes) within the samples. This could be attributed to the high preheating temperature of the powder bed prior to the melting process. The high preheating temperature enhances the laser absorptivity of the TiAl-based powder resulting in 'drilling; and entrapping of the gas in the wake of the laser beam during the solidification process (keyhole effect) [45,46]. The keyhole effect phenomenon occurs because of excessive energy absorption into the powder bed [46]. Despite the presence of the pores in the TiAl samples the current approach of maintaining a high preheating temperature throughout the manufacturing process as proposed by Caprio [27], have demonstrated that the goal of manufacturing the crack-free TiAl components via LPBF is becoming a reality. The next step is how to produce the crack-free samples without pores. This could be possibly achieved by determining the optimum process parameters (laser power, scanning speed, powder layer thickness) that could be used to manufacture the samples without pores at such a high preheating temperature of the powder bed prior to the melting process. The process parameters and the thermophysical properties of the TiAl powder determined the laser energy absorption [16], hence determining the ideal process parameters at the preheating temperature would possibly eliminate the pores. Based on the effort made so far, it could be predicted that the possibility of using the LPBF process to manufacture crack-free and pore-free TIAl-based 3D structures for industrial application is very near as the LPBF technology is gradually attaining maturity.

Another emerging approach that could be used to manufacture crack-free TiAl-based components via LPBF is using the third generation TiAl-based alloys (TNM) with a high composition of $\beta$ stabilizing elements such as $\mathrm{Nb}$ and Mo. This was demonstrated by Löber et al. [47]. The authors used TNM-B1 (Ti-Al28.9-Nb9.68-Mo2.26B0.024 wt.\%) powder with high $\beta$ stabilizing elements ( $\mathrm{Nb}$ and $\mathrm{Mo}$ ) to produced crack-free TiAl-based components. The microstructure of the TNM alloy generally consists of a duplex structure of $\beta$ and $\alpha_{2}$ grains with some $\gamma$ lamellae in $\alpha_{2} / \gamma$ colonies. It could be inferred that the high composition of the $\beta$ stabilizing elements and the low content of $\mathrm{Al}$ in the TiAl-based alloy change the lasermatter interaction [48] of the powder bed during the $\mathrm{LPBF}$ process leading to the successful manufacturing of the crack-free components via LPBF of the TNM-B1 alloy. Asavela et al. [49] also produced TiAl alloy with only 6 wt.\% of $\mathrm{Al}$ (Ti6Al) via LPBF and obtained crackfree components. The literature reveals that a host of other researchers $[14,27,47,51]$ uses TNM powder with Al composition ( $>43 \mathrm{wt} \%$ ) could not obtain crack-free components, hence it is evident that the low $\mathrm{Al}$ contents and the high content of the $\beta$ stabilizing elements used by Löber et al. [47] enable the production of the crack-free TiAl-based components using the LPBF process. The resultant duplex microstructure obtained by Löber et al. [47] is not the ideal microstructure for high-temperature applications [20,21]. The duplex microstructure is because of substituting a high amount of the $\beta$ stabilizing elements for $\mathrm{Al}$ content. As depicted in the TiAl phase diagram (Fig. 1), the TiAl alloy phases are strongly composition and microstructure dependent, hence reduction in $\mathrm{Al}$ contents would significantly affect the phases that would be present in the TiAl-based alloy. For hightemperature applications, the right proposition of the $\mathrm{Al}$ should be added to obtain the $\mathrm{TiAl}\left(\gamma\right.$-phase) and $\mathrm{Ti}_{3} \mathrm{Al}$ $\left(\alpha_{2}\right.$-phase).

Nevertheless, the addition of the $\beta$ stabilizing elements not only enhances the possible production of crack-free TiAl-based alloys but also improved the ductility, damage tolerance at room temperature, and workability of the TiAl-based alloys at elevated temperatures [47,51]. However, the $\beta$ stabilizing elements should be introduced cautiously in consideration of the resultant microstructural phases that might be present and the intended application of the alloy.

\section{Conclusion}

The TiAl-based alloys still have the center stage as the most promising alloy for high-temperature applications which can replace the heavyweight Ni-based superalloys. The conventional methods and EBM manufacturing process was applied to manufacture the alloy 'successfully' with some noticeable drawbacks. Redesigning the LPBF manufacturing system by introducing preheating systems that can maintain the temperature of the previously solidified layers and the powder bed at $800{ }^{\circ} \mathrm{C}$ before the melting of the deposited powder gave some encouraging results. The addition of high composition of $\beta$ stabilizing elements could also assist in manufacturing crack-free TiAl-based alloy. However, this should be done cautiously considering the resultant microstructure and the phases that would be present in the alloy and the intended application of the TNM alloy.

Acknowledgement. This work is based on research supported by the Collaborative Program in Additive Manufacturing (Contract No CSIR-NLC-CPAM-18-MOA-CUT-01).

\section{References}

1. J. Lapin, TiAl-based alloys: Present status and future perspectives, In Conference proceedings METAL, 2009

2. S.F. Clark, 787 propulsion system, Aero Quart. 3 (2012) $5-13$

3. B.P. Bewlay, S. Nag, A. Suzuki, M.J. Weimer, TiAl alloys in commercial aircraft engines, Mater. High Temperatur. 33 (2016) 549-559

4. C.T. Liu, J.H. Schneibel, P.J. Maziasz, J.L. Wright, D.S. Easton, Tensile properties and fracture toughness of TiAl alloys with controlled microstructures, Intermetallics 4 (1996) 429-440

5. C.M. Austin, Current status of gamma Ti aluminides for aerospace applications, Curr. Opin. Solid State Mater. Sci. 4 (1999) 239-242

6. T. Tetsui, K. Shindo, S. Kaji, S. Kobayashi, M. Takeyama, Fabrication of TiAl components by means of hot forging and machining, Intermetallics 13 (2005) 971-978 
7. D. $\mathrm{Hu}, \mathrm{X} . \mathrm{Wu}$, M.H. Loretto, Advances in optimisation of mechanical properties in cast TiAl alloys, Intermetallics $\mathbf{1 3}$ (2005) 914-919

8. Y.W. Kim, D.M. Dimiduk, Progress in the understanding of gamma titanium aluminides, J. Minerals Metals Mater. Soc. 43 (1991) 40-47

9. W.E. Voice, M. Henderson, E.F. Shelton, X. Wu, Gamma titanium aluminide, TNB, Intermetallics 13 (2005) 959-964

10. X. Wu, Review of alloy and process development of TiAl alloys, Intermetallics 14 (2006) 1114-1122

11. P.M.W. Cobbinah, Solid-state processing route, mechanical behaviour, and oxidation resistance of TiAl alloys, Adv. Mater. Sci. Eng. (2019)

12. M. Thomas, T. Malot, P. Aubry, C. Colin, T. Vilaro, P. Bertrand, The prospects for additive manufacturing of bulk TiAl alloy, Mater. High Temperatur. 33 (2016) 571-577

13. T.C. Dzogbewu, Y.D. Arthur, Comparative studies of locally produced and imported low-carbon steels on the Ghanaian market, J. Natur. Sci. 1 (2013) 15-22

14. T. Vilaro, V. Kottman-Rexerodt, M. Thomas, C. Colin, P. Bertrand, L. Thivillon, S. Abed, V. Ji, P. Aubry, P. Peyre, T. Malot, Direct fabrication of a Ti-47Al-2Cr-2Nb alloy by selective laser melting and direct metal deposition processes, Adv. Mater. Res. 89 (2010) 586-591

15. D. Cormier, O.L.A. Harrysson, T. Mahale, H. West, Freeform fabrication of titanium aluminide via electron beam melting using prealloyed and blended powders, Res. Lett. Mater. Sci. (2007) 1-4

16. T.C. Dzogbewu, Direct metal laser sintering of titanium alloys for biomedical applications, Central University of Technology, Free State, Doctoral dissertation, 2017

17. I. Yadroitsau, Direct manufacturing of 3D objects by selective laser melting of metal powders, Saint-Etienne, Doctoral dissertation, 2008

18. T.C. Dzogbewu, L. Monaheng, I. Yadroitsava, W.B. Du Preez, I. Yadroitsev, Finite element analysis in design of DMLS mandible implants, in Challenges for Technology Innovation: An Agenda for the Future (CRC Press, 2017), pp. $155-160$

19. H. Clemens, H. Kestler, Processing and applications of intermetallic $\boldsymbol{\gamma}$-TiAl-based alloys, Adv. Eng. Mater. 2 (2000) $551-570$

20. I. Gil, M.A. Muñoz-Morris, D.G. Morris, The effect of heat treatments on the microstructural stability of the intermetallic Ti-46.5 Al-2W-0.5 Si, Intermetallics 9 (2001) 373-385

21. D. Srivastava, Microstructural characterization of the $\boldsymbol{\gamma}$-TiAl alloy samples fabricated by direct laser fabrication rapid prototype technique, Bull. Mater. Sci. 25 (2002) 619-633

22. L.E. Murr, S.M. Gaytan, A. Ceylan, E. Martinez, J.L. Martinez, D.H. Hernandez, B.I. Machado, D.A. Ramirez, F. Medina, S. Collins, R.B. Wicker, Characterization of titanium aluminide alloy components fabricated by additive manufacturing using electron beam melting, Acta Mater. 58 (2010) 1887-1894

23. A.R. Rastkar, B. Shokri, Surface transformation of Ti-45Al2Nb-2Mn-1B titanium aluminide by electron beam melting, Surf. Coat. Technol. 204 (2010) 1817-1822

24. N. Shen, K. Chou, Thermal modeling of electron beam additive manufacturing process: powder sintering effects, in International Manufacturing Science and Engineering Conference, 287, ASME, 2012
25. S. Biamino, A. Penna, U. Ackelid, S. Sabbadini, O. Tassa, P. Fino, M. Pavese, P. Gennaro, C. Badini, Electron beam melting of Ti-48Al-2Cr-2Nb alloy: Microstructure and mechanical properties investigation, Intermetallics $\mathbf{1 9}$ (2011) $776-778$

26. L. Löber, S. Biamino, U. Ackelid, S. Sabbadini, P. Epicoco, P. Fino, J. Eckert, Comparison of selective laser and electron beam melted titanium aluminides, in Solid freeform fabrication proceedings, University of Texas, Austin, 2011

27. L. Caprio, A.G. Demir, G. Chiari, B. Previtali, Defect-free laser powder bed fusion of $\mathrm{Ti}-48 \mathrm{Al}-2 \mathrm{Cr}-2 \mathrm{Nb}$ with a high temperature inductive preheating system, J. Phys.: Photonics 2 (2020) 024001

28. Y.L.S.J. Liu, H.L. Wang, W.T. Hou, Y.L. Hao, R. Yang, T.B. Sercombe, L.C. Zhang, Microstructure, defects and mechanical behavior of beta-type titanium porous structures manufactured by electron beam melting and selective laser melting and selective laser melting, Acta Materialia 113 (2016) 56-67

29. T.C. Dzogbewu, L. Monaheng, J. Els, I. van Zyl, W.B. Du Preez, I. Yadroitsava, I. Yadroitsev, Evaluation of the compressive mechanical properties of cellular dmls structures for biomedical applications, in 17th Annual Conference of the Rapid Product Development Association of South Africa, 2016

30. I. Yadroitsev, I. Smurov, Surface morphology in selective laser melting of metal powders, Phys. Proc. 12 (2011) 264-270

31. J. Gussone, G. Garces, J. Haubrich, A. Stark, Y.C. Hagedorn, N. Schell, G. Requena, Microstructure stability of $\gamma$-TiAl produced by selective laser melting, Scr. Mater. 130 (2017) 110-113

32. U.S. Bertoli, G. Guss, S. Wu, M.J. Matthews, J.M. Schoenung, In-situ characterization of laser-powder interaction and cooling rates through high-speed imaging of powder bed fusion additive manufacturing, Mater. Des. 135 (2017) 385-396

33. Q. Shi, D. Gu, M. Xia, S. Cao, T. Rong, Effects of laser processing parameters on thermal behavior and melting/ solidification mechanism during selective laser melting of TiC/Inconel 718 composites, Opt. Laser Technol. 84 (2016) 9-22

34. J. Gussone, Y.C. Hagedorn, H. Gherekhloo, G. Kasperovich, T. Merzouk, J. Hausmann, Microstructure of $\gamma$-titanium aluminide processed by selective laser melting at elevated temperatures, Intermetallics 66 (2015) 133-140

35. S. Das, J. McWilliam, B. Wu, J.J. Beaman, Design of a high temperature workstation for the selective laser sintering process, in International Solid Freeform Fabrication Symposium, 1991

36. M. Agarwala, D. Bourell, J. Beaman, H. Marcus, J. Barlow, Direct selective laser sintering of metals, Rapid Prototyp. J. 1 (1995) 26-36

37. J. McWilliams, C. Hysinger, J.J. Beaman, Design of a high temperature process chamber for the selective laser sintering process, in International Solid Freeform Fabrication Symposium, 1992

38. N.T. Aboulkhair, N.M. Everitt, I. Ashcroft, C. Tuck, Reducing porosity in AlSi10Mg parts processed by selective laser melting, Addit. Manufactur. 1 (2014) 77-86

39. A.G. Demir, B. Previtali, Investigation of remelting and preheating in SLM of $18 \mathrm{Ni} 300$ maraging steel as corrective 
and preventive measures for porosity reduction, Int. J. Adv. Manufactur. Technol. 93 (2017) 2697-2706

40. M. Colopi, A.G. Demir, L. Caprio, B. Previtali, Limits and solutions in processing pure $\mathrm{Cu}$ via selective laser melting using a high-power single-mode fiber laser, Int. J. Adv. Manufactur. Technol. 104 (2019) 24

41. J. Wilkes, Y.C. Hagedorn, W. Meiners, K. Wissenbach, Additive manufacturing of $\mathrm{ZrO} 2-\mathrm{Al} 2 \mathrm{O} 3$ ceramic components by selective laser melting, Rapid Prototyp. J. 19 (2013) 51-57

42. K. Kempen, B. Vrancken, S. Buls, L. Thijs, J. Van Humbeeck, J.P. Kruth, Selective laser melting of crack-free high density M2 high speed steel parts by baseplate preheating, J. Manufactur. Sci. Eng. 136 (2014) 061026

43. H. Ali, L. Ma, H. Ghadbeigi, K. Mumtaz, In-situ residual stress reduction, martensitic decomposition and mechanical properties enhancement through high temperature powder bed pre-heating of selective laser melted Ti6Al4V, Mater. Sci. Eng. A 695 (2017) 211-220

44. Y.C. Hagedorn, J. Risse, W. Meiners, N. Pirch, K. Wissenbach, R. Poprawe, Processing of nickel based superalloy MAR M-247 by means of high temperatureselective laser melting (HT-SLM), in Proc 6th Int Conf Adv Res Virtual Rapid Prototyp (2013)
45. W.E. King, H.D. Barth, V.M. Castillo, G.F. Gallegos, J.W. Gibbs, D.E. Hahn, C. Kamath, A.M. Rubenchik, Observation of keyhole-mode laser melting in laser powder-bed fusion additive manufacturing, J. Mater. Process. Technol. 214 (2014) 2915-2925

46. T.C. Dzogbewu, Laser powder bed fusion of Ti15Mo, Results Eng. (2020) 100155

47. L. Löber, F.P. Schimansky, U. Kühn, F. Pyczak, J. Eckert, Selective laser melting of a beta-solidifying TNM-B1 titanium aluminide alloy, J. Mater. Process. Technol. 214 (2014) 1852-1860

48. W. Ge, C. Guo, F. Lin, Effect of process parameters on microstructure of TiAl alloy produced by electron beam selective melting, Proc. Eng. 81 (2014) 1192-1197

49. A. Zenani, T.C. Dzogbewu, W.B. Du Preez, I. Yadroitsev, Optimum process parameters for direct metal laser sintering of Ti6Al Powder Blend, Univ. J. Mech. Eng. 8 (2020) $170-182$

50. H. Okamoto, H. Okamoto, Phase diagrams for binary alloys (ASM International, Materials Park, OH, 2000)

51. B. Tang, B. Zhu, W. Bi, Y. Liu, J. Li, Effect of microstructure on the high-cycle fatigue behavior of $\mathrm{Ti}$ (43-44) Al4Nb1Mo (TNM) alloys, Metals 9 (2019) 1043

Cite this article as: Thywill Cephas Dzogbewu, Additive manufacturing of TiAl-based alloys, Manufacturing Rev. 7, 35 (2020) 